\title{
Serotonin and Hallucinogens
}

\author{
G.K. Aghajanian, M.D. and G.J. Marek, M.D., Ph.D.
}

This brief review traces the serotonin (5-HT) hypothesis of the action of hallucinogenic drugs from the early 1950s to the present day. There is now converging evidence from biochemical, electrophysiological, and behavioral studies that the two major classes of psychedelic hallucinogens, the indoleamines (e.g., LSD) and the phenethylamines (e.g., mescaline), have a common site of action as partial agonists at $5-\mathrm{HT}_{2 \mathrm{~A}}$ and other $5-\mathrm{HT}_{2}$ receptors in the central nervous system. The noradrenergic locus coeruleus and the cerebral cortex are among the regions where hallucinogens have prominent effects through their actions upon a $5-\mathrm{HT}_{2 \mathrm{~A}}$ receptors. Recently, we have observed a novel effect of hallucinogens-a $5-\mathrm{HT}_{2 A}$ receptor-mediated enhancement of nonsynchronous, late components of glutamatergic excitatory postsynaptic potentials at apical dendrites of layer $V$ cortical pyramidal cells. We propose that an effect of hallucinogens upon glutamatergic transmission in the cerebral cortex may be responsible for the higher-level cognitive, perceptual, and affective distortions produced by these drugs. [Neuropsychopharmacology 21:16S-23S, 1999] (C) 1999 American College of Neuropsychopharmacology. Published by Elsevier Science Inc.
KEY WORDS: Serotonin; LSD; Hallucinogens; 5- $\mathrm{HT}_{2 \mathrm{~A}}$ receptors; Glutamatergic; Excitatory postsynaptic potentials; Cerebral cortex; Locus coeruleus

The accidental discovery in 1943 of the hallucinogenic properties of the synthetic ergoline compound LSD (dlysergic acid diethylamide) by the chemist Albert Hoffman is well known. Five years later, in 1948, serotonin (later determined to be 5-hydroxytryptamine or 5-HT) was found in bovine blood serum (Rapport et al. 1948). Then, in 1953, during a routine survey of various tissues, relatively high concentrations of 5-HT were found in brain (Twarog and Page 1953). Shortly thereafter, based on the observation that LSD could antagonize 5-HT in peripheral tissues-plus the structural similarity between these two indole-containing structures (Figure 1) - it was proposed independently by Gaddum

From the Department of Psychiatry (GKA) and Department of Pharmacology (GJM), Yale University School of Medicine and the Connecticut Mental Health Center, New Haven, Connecticut

Address correspondence to: G. K. Aghajanian, M.D., Connecticut. Mental Health Center, 34 Park St., New Haven, CT 06508.

Received October 19, 1998; revised November 20, 1998; accepted November 30, 1998. and Hammeed (1954) and Woolley and Shaw (1954) that the hallucinogenic effects of LSD might result from an antagonism of 5-HT in the central nervous system. This hypothesis was soon modified to include the possibility that LSD could mimic as well as antagonize the actions of 5-HT (Shaw and Woolley 1956). The 5-HT hypothesis was later extended to include such simple indoleamine hallucinogens as psilocin, which are close structural analogs of 5-HT (Figure 1) and the phenethylamine hallucinogens, such as mescaline. Mescaline, despite differences in chemical structure (Figure 1), displayed similar clinical effects and cross tolerance with LSD in human studies (Balestrieri and Fontanari 1959), suggesting that the indoleamine (including ergoline) and phenethylamine classes of hallucinogens may share a common mechanism of action or final common pathway. By the end of the 1950s, three classical questions about the relationship between 5-HT and the hallucinogens had been set into place. First, do the hallucinogens produce their effects through an action upon the central 5-HT system? Second, are hallucinogens agonists or antagonists at 5-HT receptors? Third, do indoleamine and phenethylamine hallucinogens share a common site of action? 
<smiles></smiles>

$5-\mathrm{HT}$<smiles>CN(C)CCc1c[nH]c2cccc(O)c12</smiles>

psilocin

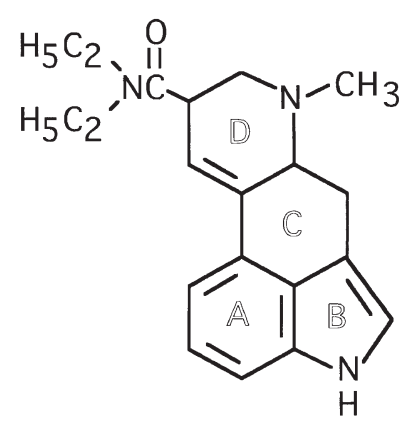

LSD
Figure 1. Structural formulae for serotinin (5-HT), LSD, mescaline, and the simple indoleamine hallucinogen psilocin. The chemical structures are drawn in relation to the A, B, $\mathrm{C}$, and D rings of LSD to emphasize common structural features such as the indolethylamine nucleus of 5-HT and psilocin and the phenethylamine nucleus shared by LSD and mescaline.

\section{NEURONAL ACTIONS OF HALLUCINOGENIC DRUGS}

\section{Effects of Hallucinogens on 5-HT Neurons of the Raphe Nuclei}

The identification of 5-HT as a neurotransmitter was not achieved until the mid-1960s, when monoaminergic neuronal pathways in the brain were discovered and mapped by histochemical fluorescence methods (Dählstrom and Fuxe 1964). These maps, which revealed that 5-HT neuronal cell bodies were clustered in the raphe nuclei of the brainstem, provided the basis for singlecell electrophysiological recordings from identified 5-HT neurons. LSD was found to have a potent inhibitory effect upon the tonically firing 5-HT neurons of the dorsal raphe nucleus (Aghajanian et al. 1968); the local application of LSD by microiontophoresis indicated that the inhibition was through a direct action on the somatodendritic region of 5-HT neurons (Aghajanian et al. 1972). A reduction in 5-HT cell firing rate was consistent with earlier biochemical findings of reduced 5-HT turnover in brain after LSD (Freedman 1961). Simple indoleamine hallucinogens such as DMT (N,N-dimethyltryptamine) and psilocin were also shown to inhibit 5-HT neurons in the raphe nuclei (Aghajanian and Haigler 1975). However, although systemically administered mescaline and various other substituted phenethylamine hallucinogens were able to suppress the firing of a subset of 5-HT neurons (Aghajanian et al. 1970), they were unlike the indoleamines in that they worked through an indirect mechanism rather than through a direct inhibition raphe neurons (Haigler and Aghajanian 1973). Thus, a direct, postsynaptic inhibition of 5-HT neurons did not seem to represent a unitary cellular mechanism for the action of indoleamine and phenethylamine hallucinogens.

In subsequent years, the delineation of multiple 5-HT receptor subtypes by radiolabeled ligand binding and molecular methods (see Hoyer et al. 1994) provided a basis for explaining the difference between the effects of the indoleamine and phenethylamine hallucinogens on 5-HT neurons. Serotonergic raphe neurons have a high density of 5- $\mathrm{HT}_{1 \mathrm{~A}}$ but not other subtypes of 5-HT receptors. LSD is a potent agonist at $5-\mathrm{HT}_{1 \mathrm{~A}}$ somatodendritic autoreceptors, thus accounting for its direct inhibitory effect on raphe neurons (see Aghajanian 1995). On the other hand, mescaline and other phenethylamines have negligible affinity for $5-\mathrm{HT}_{1 \mathrm{~A}}$ receptors, explaining their inability to inhibit directly 5-HT raphe neurons. The action of $\mathrm{LSD}$ at $5-\mathrm{HT}_{1 \mathrm{~A}}$ autoreceptors is shared by a number of selective $5-\mathrm{HT}_{1 \mathrm{~A}}$ agonists, such as buspirone, which are known from clinical studies to have anxiolytic rather than hallucinogenic effects. Thus, no correlation exists between the activity of various drugs at $5-\mathrm{HT}_{1 \mathrm{~A}}$ receptors and the presence or absence of hallucinogenic properties.

\section{Affinity for 5- $\mathrm{HT}_{2}$ Receptors Correlates with Hallucinogenic Potency}

Glennon, Titeler, and their colleagues showed that there is an excellent correlation between the affinity of both indoleamine and phenethylamine hallucinogens for 5- $\mathrm{HT}_{2}$ receptors and hallucinogenic potency in humans (Glennon et al. 1984; Titeler et al. 1988). Indeed, among all the known 5-HT receptor subtypes, affinity for $5-\mathrm{HT}_{2}$ receptors is the only one shared by these two major classes of hallucinogens (Table 1). Based on this seminal work, subsequent research on hallucinogens has focused on interactions with 5- $\mathrm{HT}_{2}$ receptors, particularly the $5-\mathrm{HT}_{2 \mathrm{~A}}$ receptor. Unlike $5-\mathrm{HT}_{1 \mathrm{~A}}$ receptors, $5-\mathrm{HT}_{2 \mathrm{~A}}$ receptors are not located presynaptically on 5-HT cell bodies but rather are found upon subpopulations of neurons in postsynaptic regions. Although quantitative autoradiographic studies show the presence of $5-\mathrm{HT}_{2 \mathrm{~A}}$ receptors in multiple regions of the brain, including the olfactory bulb, claustrum, nucleus accumbens, olfactory tubercle, facial nucleus, and the 
n. tractus solitarius, the preponderance of these receptors are located in the cerebral cortex (Lopez-Gimenez et al. 1997; Pazos and Palacios 1985); a high density of $5-\mathrm{HT}_{2 \mathrm{~A}}$ receptor mRNA has been demonstrated by in situ hybridization in similar locations (Mengod et al. 1990). Recent immunocytochemical studies have demonstrated a particularly high density of $5-\mathrm{HT}_{2 \mathrm{~A}}$ receptors in the apical dendrites of cortical pyramidal cells (Jakab and Goldman-Rakic 1998; Willins et al. 1997).

Actions at 5- $\mathrm{HT}_{2 \mathrm{C}}$ receptors, which have been associated with anxiogenic responses (Kennett et al. 1997), could also contribute to the effects of hallucinogens. However, for purposes of illustration, the focus of this review is on two brain regions, the locus coeruleus and the cerebral cortex, where the physiological actions of both LSD and the phenethylamine hallucinogens have been shown to be mediated primarily by $5-\mathrm{HT}_{2 \mathrm{~A}}$ receptors.

\section{Hallucinogens Enhance Sensory Responses in the Locus Coeruleus via $5-\mathrm{HT}_{2 \mathrm{~A}}$ Receptors}

The locus coeruleus (LC) consists of two dense clusters of noradrenergic neurons located bilaterally in the upper pons at the lateral border of the 4 th ventricle. The LC, which projects diffusely to virtually all regions of the neuraxis, receives an extraordinary convergence of somatic, visceral, and other sensory inputs from all regions of the body, has been likened to a novelty detector for salient external stimuli (Aston-Jones and Bloom 1981; Cedarbaum and Aghajanian 1978). In this context, it is of interest that the systemic administration of LSD, mescaline, or other psychedelic hallucinogens in anesthetized rats, although decreasing spontaneous activity, produces a paradoxical facilitation of the activation of LC neurons by sensory stimuli (Aghajanian 1980; Rasmussen and Aghajanian 1986); this effect is not through a direct action on LC cell bodies, because it cannot be mimicked by the local, microiontophoretic application of the drugs. The effects of hallucinogens on LC neurons can be reversed by low intravenous doses of selective $5-\mathrm{HT}_{2}$ antagonists, such as ritanserin (Rasmussen and Aghajanian 1986). Antipsychotic drugs are also able to reverse the actions of hallucinogens in the locus

Table 1. Interaction of LSD and Phenethylamine Hallucinogens with 5-HT Receptor Subtypes (Glennon 1990; Marek and Aghajanian 1996a)

\begin{tabular}{lcc}
\hline Receptor Subtype & LSD & Phenethylamines \\
\hline $5-\mathrm{HT}_{1 \mathrm{~A}}$ & + & - \\
$5-\mathrm{HT}_{1 \mathrm{D}}$ & + & - \\
$5-\mathrm{HT}_{2 \mathrm{~A} / 2 \mathrm{C}}$ & + & + \\
$5-\mathrm{HT}_{3}$ & - & - \\
$5-\mathrm{HT}_{4}$ & - & $?$ \\
$5-\mathrm{HT}_{5}$ & + & - \\
$5-\mathrm{HT}_{6 / 7}$ & + & - \\
\hline
\end{tabular}

coeruleus at doses correlating with their affinity for $5-\mathrm{HT}_{2 \mathrm{~A}}$ but not dopamine and adrenergic receptors (Rasmussen and Aghajanian 1988). Studies on the mechanism by which hallucinogens produce their effects on LC neurons have shown that the decrease in spontaneous firing caused by the $5-\mathrm{HT}_{2}$ agonist DOI (1$\{2,5$-dimethoxy-4-iodophenyl $\}$-2-aminopropane) is via activation of inhibitory inputs acting upon $\mathrm{GABA}_{\mathrm{A}}$ receptors; whereas, the enhancement of phasic sensory responses is via activation of excitatory inputs acting upon NMDA (N-methyl-D-aspartate) receptors (Chiang and Aston-Jones 1993).

Because the effects of systemically administered hallucinogens are through an activation of afferent inputs rather than through a direct action upon LC cell bodies, the LC itself cannot be used as a model for studying the direct cellular actions of hallucinogens. Nevertheless, the effects of the hallucinogens upon the LC are of interest, because this nucleus receives such an extraordinarily widespread convergence of sensory information, both somatosensory and visceral, relaying this information to virtually all other parts of the neuraxis, including the cerebral cortex.

\section{5-HT $\mathrm{HA}_{2 \mathrm{~A}}$ Receptors Enhance Glutamate Release in Neocortex}

The ubiquitous effects of hallucinogens on such complex processes as cognition, perception, and mood suggest the involvement of the cerebral cortex. The direct, postsynaptic effect of 5-HT in the cortex are variable: depolarization, hyperpolarization, or no change, depending upon whether the effects of excitatory $5-\mathrm{HT}_{2}$ receptors or inhibitory $5-\mathrm{HT}_{1 \mathrm{~A}}$ receptors are predominant in any given layer $\mathrm{V}$ pyramidal cell (Aghajanian and Marek 1997; Araneda and Andrade 1991; Tanaka and North 1993). However, the most striking effect of 5 -HT in cortical regions is to increase postsynaptic potentials (PSPs). In earlier studies, we had found that $5-\mathrm{HT}$, via 5- $\mathrm{HT}_{2 \mathrm{~A}}$ receptors, induces inhibitory postsynaptic potentials (IPSPs) in layer II pyramidal cells of rat piriform cortex (a paleocortical region) through the direct excitation of a subset of GABAergic interneurons (Gellman and Aghajanian 1993; Sheldon and Aghajanian 1990); hallucinogens, acting as potent partial 5- $\mathrm{HT}_{2 \mathrm{~A}}$ agonists, have similar effects (Marek and Aghajanian 1996a). In contrast, we have found recently that synaptic potentials induced by $5-\mathrm{HT}$ receptor activation in layer $\mathrm{V}$ pyramidal cells of the neocortex are predominantly excitatory rather than inhibitory (Aghajanian and Marek 1997), a finding that was surprising in view of the earlier work in piriform cortex. Thus, only $\sim 15 \%$ of 5-HT-induced synaptic potentials in neocortex are blocked by the $\mathrm{GABA}_{\mathrm{A}}$ antagonist bicuculline; whereas, most synaptic potentials are blocked by the AMPA glutamatergic receptor antagonist LY293558, indicating 
that they represent largely excitatory postsynaptic potentials (EPSPs) rather than IPSPs. Nevertheless, as with IPSPs in the piriform cortex, the EPSCs induced by 5 - $\mathrm{HT}$ in neocortex are mediated by $5-\mathrm{HT}_{2 \mathrm{~A}}$ receptors as they are blocked by low concentrations of the highly selective 5- $\mathrm{HT}_{2 \mathrm{~A}}$ antagonist MDL100,907 (Aghajanian and Marek 1997). Although we have observed that 5-HT increases EPSCs throughout the neocortex, this effect is most pronounced in the medial prefrontal cortex, where there is an increased density of $5-\mathrm{HT}_{2 \mathrm{~A}}$ receptors as compared to more posterior regions. NE also increases glutamatergic excitatory postsynaptic potentials in layer $\mathrm{V}$ pyramidal cells (Marek and Aghajanian 1996b), but to a much lesser extent than 5-HT. Nevertheless, because of the phasic quality of LC neuronal responses to sensory stimuli, sudden NE-induced increases in glutamate release could contribute to some of the distinctive effects of hallucinogenic drugs such as synesthesias.

Whole-cell patch clamp recordings have demonstrated that 5-HT induces a small, but significant, increase in the amplitude of spontaneous EPSCs, an effect that may involve a postsynaptic amplification mechanism (Aghajanian and Marek 1997). Such a postsynaptic effect is consistent with the finding of a high density of 5- $\mathrm{HT}_{2 \mathrm{~A}}$ receptor immunoreactivity in the apical dendrites of cortical pyramidal cells (Jakab and GoldmanRakic 1998; Willins et al. 1997). However, the most pronounced effect of 5-HT in neocortex is to increase the frequency of EPSCs (Aghajanian and Marek 1997). Classically, changes in the frequency of synaptic currents or potentials are considered presumptive evidence for modulation of presynaptic function. Consistent with this model, activation of $\mu$-opiate receptors (Marek and Aghajanian 1998a) and group II/III metabotropic glutamate receptors (Marek and Aghajanian 1998b) both suppress 5-HT-induced EPSCs through a presynaptic rather than postsynaptic action upon layer $\mathrm{V}$ pyramidal cells. In general, these findings suggest that activation of $5-\mathrm{HT}_{2 \mathrm{~A}}$ receptors increases the release of glutamate onto layer $\mathrm{V}$ pyramidal cells through a presynaptic mechanism.

\section{A Focal Mechanism for $5-\mathrm{HT}_{2 \mathrm{~A}}$-Induced Glutamate Release onto Apical Dendrites of Layer V Pyramidal Cells}

A novel mechanism, independent of impulse flow, seems to be involved in the increase in glutamate release induced by $5-\mathrm{HT}_{2 \mathrm{~A}}$ receptor activation. Blockade of 5-HT-induced EPSCs by bath application of the fast sodium channel blocker tetrodotoxin (TTX) or perfusion of the slice with a solution containing no added calcium ("0" calcium) would generally suggest that 5-HT had activated glutamatergic cells in the slice, leading to an impulse-flow-dependent release of glutamate. Several lines of evidence argue against this conventional interpretation. First, we rarely found any neurons induced to fire by bath application of 5-HT (unlike our experience in the piriform cortex, where we readily found GABAergic interneurons excited by 5-HT). Second, none of the pyramidal cells (a potential source of intracortical excitatory inputs) in our sample were depolarized by 5-HT sufficiently to reach threshold for firing. Third, EPSCs could be induced by the microiontophoresis of 5-HT onto the apical dendrites of layer V pyramidal cells, but no cell firing was detected while recording extracellularly through the microiontophoretic electrode (Aghajanian and Marek 1997). Together, these experiments suggest that 5-HT-induces EPSCs in neocortical cells via a focal mechanism that does not require impulse flow.

\section{5- $\mathrm{HT}_{2 \mathrm{~A}}$ Receptors and Asynchronous Transmission in the Cerebral Cortex}

Because the microiontophoretic experiments indicate that 5-HT-induced EPSCs do not result from an increase in impulse flow in excitatory afferents, we were prompted to explore alternative mechanisms of transmitter release. Classically, two major types of vesicular neurotransmitter release have been characterized in experiments analyzing electrically evoked synaptic potentials (Goda and Stevens 1994). The first type of neurotransmitter release, termed synchronous release, is closely coupled in an almost immediate fashion to the action potential invasion of the nerve terminals with a subsequent flooding of $\mathrm{Ca}^{2+}$ into the terminal through voltage-gated $\mathrm{Ca}^{2+}$ channels. This is the form of neurotransmitter release that we typically envision. However, analysis of "synaptic noise" shows that there is also a slow, asynchronous phase of transmitter release, characterized by the presence of small EPSCs with a slightly longer latency $(\sim 50 \mathrm{~ms})$ than the synchronous EPSC, which can persist for $\sim 500-1,000$ ms following the evoked synchronous EPSC. This form of release is sustained by low levels of residual $\mathrm{Ca}^{2+}$ remaining within the terminal following the initial wave of $\mathrm{Ca}^{2+}$ influx.

One of several distinguishing characteristics for this alternative mechanism of transmitter release is that $\mathrm{Sr}^{2+}$ is able to substitute for $\mathrm{Ca}^{2+}$ for asynchronous, but not synchronous release (Goda and Stevens 1994). This feature seems to be a result of two different isoforms of synaptotagmin being differentially involved in the two alternative release mechanisms ( $\mathrm{Li}$ et al. 1995). We are now investigating the possibility that the 5-HT-induced EPSCs result from an activation of the asynchronous release pathway. Consistent with this idea, in preliminary experiments, we have found that $\mathrm{Sr}^{2+}$ is highly effective in enabling 5-HT to induce EPSCs in the absence of $\mathrm{Ca}^{2+}$ (Aghajanian and Marek 1998).

Recently, we have found that LSD (Figure 2) and other hallucinogenic drugs, acting as partial agonists at 

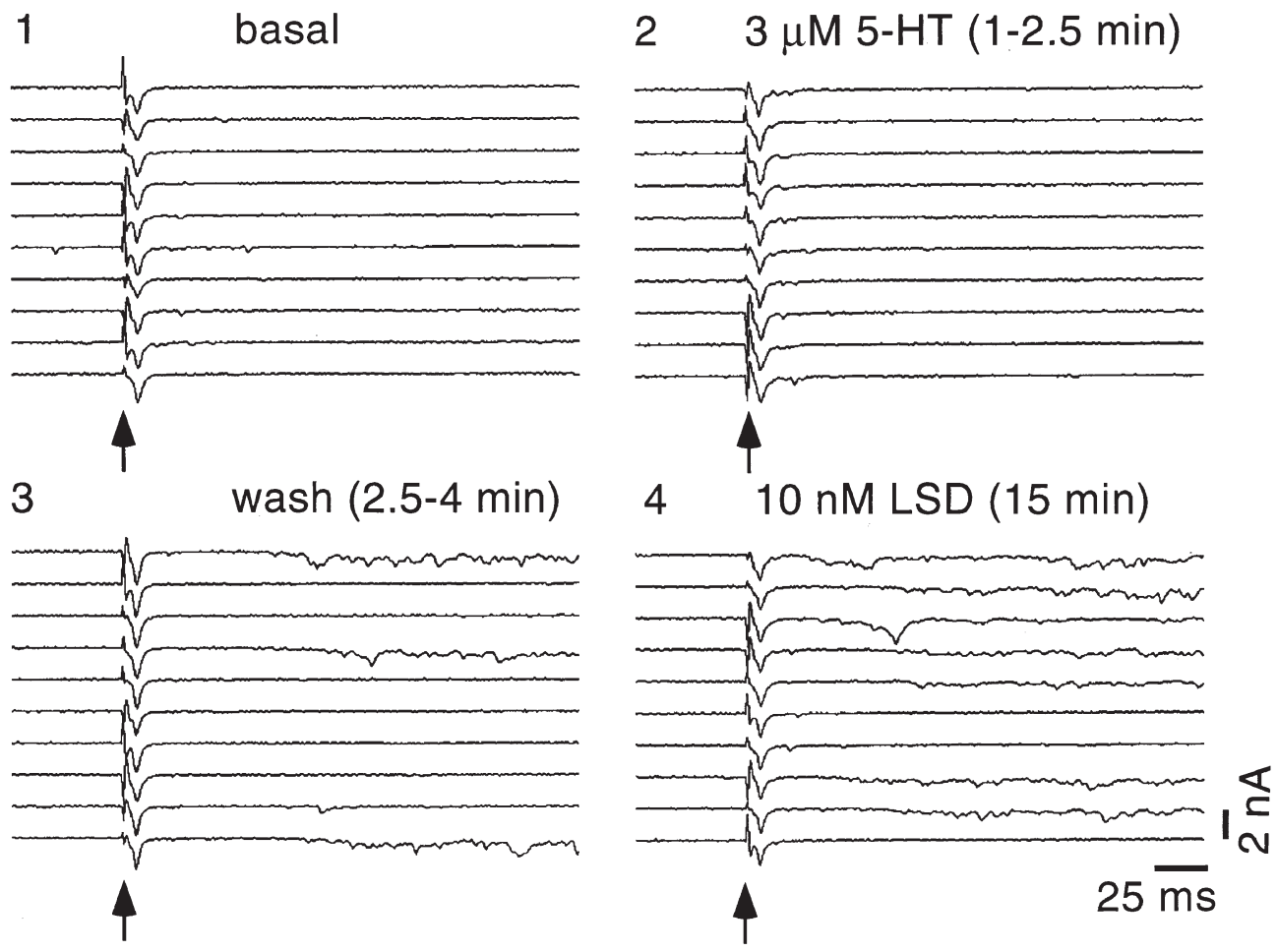

Figure 2. Effects of 5-HT, 5-HT washout, and LSD on electrically evoked EPSCs (evEVSCs)in a layer V pyramidal cell of medial prefrontal cortex. (1) shows responses to 10 consecutive stimuli (arrowheads), where only short latency synchronous EPSCs are evoked. (2) After a 1 to 2.5 min application of 5-HT $(3 \mu \mathrm{M})$, there is little change in amplitude of the synchronous evoked EPSC and no increase in late components of the EPSC. (3) After a short washout of 5-HT (2.5-4 min), sustained late or nonsynchronous EPSCs appear after 3/10 stimuli; recovery to the basal state occurred after an additional 10 min of washout (not shown). (4) Subsequent perfusion with a low concentration of LSD (10 nM) resulted in a large increase in the occurrence of the late, nonsynchronous component of the EPSCs (7/10 sweeps) (Aghajanian and Marek 1998).

$5-\mathrm{HT}_{2 \mathrm{~A}}$ receptors, also promote a late component of electrically evoked EPSPs (Aghajanian and Marek 1998). We hypothesize that this late component, rather that representing conventional polysynaptic transmission, is mediated through the mechanism of asynchronous transmitter release, possibly involving a release of intraterminal $\mathrm{Ca}^{2+}$ stores via the phospholipase $\mathrm{C}$, inositol trisphosphate $\left(\mathrm{IP}_{3}\right)$ pathway. An enhancement of asynchronous evoked EPSPs via 5- $\mathrm{HT}_{2 \mathrm{~A}}$-receptors would provide a possible synaptic mechanism for the hallucinogenic effects of these drugs. In contrast, 5-HT itself does not promote the late component of electrically evoked release except during the washout phase, presumably because of opposing actions at $5-\mathrm{HT}_{1}$ or other non-5- $\mathrm{HT}_{2 \mathrm{~A}}$ receptors (Aghajanian and Marek 1998).

The opposition by non-5- $\mathrm{HT}_{2 \mathrm{~A}}$ receptors of $5-\mathrm{HT}_{2 \mathrm{~A}^{-}}$ mediated actions of 5-HT may explain why treatments that elevate 5-HT itself (e.g., monoamine oxidase inhibitors or selective serotonin uptake blockers) are not hallucinogenic and may, in fact, attenuate the subjective effects of hallucinogens in humans (Bonson et al. 1996; Resnick et al. 1964). Conversely, a reduction in serotonin levels or release could enhance the effects of hallucinogens (Isbell and Logan 1957; Resnick et al. 1965). By decreasing 5-HT release, a direct inhibition of 5-HT cell firing in the raphe nuclei could contribute to the effects of LSD and other indoleamine hallucinogens. Although the phenethylamines suppress the firing of only a subset 5-HT neurons (an effect mediated through an indirect rather than direct postsynaptic mechanism, see above), this action could also contribute to the hallucinogenic effects of these drugs. Despite these interesting, but subtle, differences in mechanism, the over-all subjective effects of indoleamine and phenethylamine hallucinogens have been reported to be virtually identical in side-by side comparisons in human subjects (Wolbach et al. 1962).

\section{OVERVIEW AND FUTURE DIRECTIONS}

\section{The Classical Questions}

Many of the original questions about the role of 5-HT in the action of hallucinogenic drugs can now be addressed in a highly specific manner. In the present review, neuronal actions shared by LSD and the phenethylamine hallucinogens have been described in detail for two brain regions, the LC and the cerebral cortex. In 


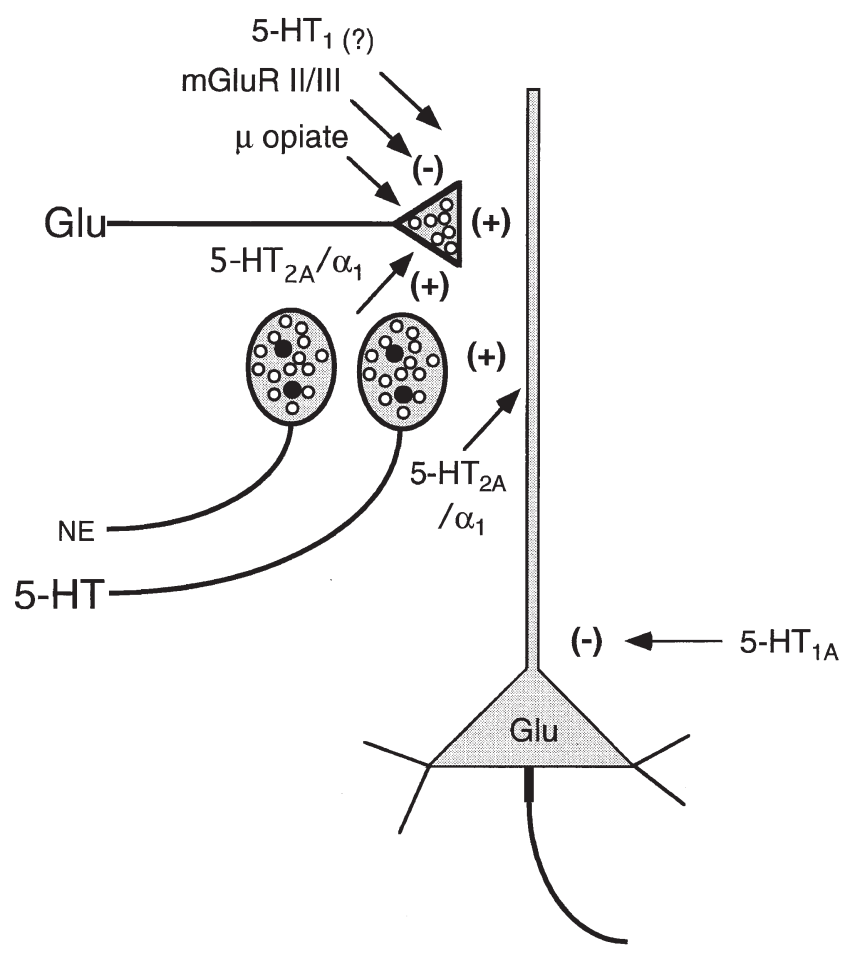

Figure 3. Schematic diagram depicting 5-HT inputs (from the raphe nuclei) and nonadrenergic (NE) inputs (from the locus coeruleus) projecting to the vicinity of the apical dendrite of a layer $\mathrm{V}$ pyramidal cell in neocortex. 5-HT, acting via $5-\mathrm{HT}_{2 \mathrm{~A}}$ receptors, is shown to induce the release of glutamate from an excitatory nerve terminal $(+)$; to a lesser extent, NE, acting via $\alpha_{1}$ receptors, also induces glutamate release. Also shown are inhibitory modulators of $5-\mathrm{HT}_{2 \mathrm{~A}^{-}}$ induced glutamate release: $\mu$ opiate, group II and III metabotropic glutamate (mGluR II/III), and as yet an uncharacterized non-5- $\mathrm{HT}_{2 \mathrm{~A}}$ receptor (possibly a $5-\mathrm{HT}_{1}$ subtype). In addition, excitatory $\left(5-\mathrm{HT}_{2 \mathrm{~A}}\right.$ and $\left.\alpha_{1}\right)$ and inhibitory $\left(5-\mathrm{HT}_{1 \mathrm{~A}}\right)$ postsynaptic effects of 5-HT and NE are shown.

these and other regions, there is evidence that both classes of hallucinogens produce their electrophysiological effects through a partial agonist action at 5- $\mathrm{HT}_{2}$ (particularly $5-\mathrm{HT}_{2 \mathrm{~A}}$ ) receptors. There is also evidence from biochemical (Sanders-Bush et al. 1988) and behavioral (Glennon 1990) studies that the effects of hallucinogens involve a partial agonist action at $5-\mathrm{HT}_{2}$ receptors. Thus, 50 years after the discovery of 5-HT, the 5-HT hypothesis of the action of both indoleamine and phenethylamine hallucinogenic drugs can be reformulated in terms of specific 5-HT receptor subtypes, with a primary focus on $5-\mathrm{HT}_{2}$ receptors.

\section{Questions-1998}

How do the discrete neuronal actions of hallucinogens, as described above, account for dramatic disruptions in cortical function produced by the hallucinogenic drugs? It is now possible to suggest regionally and neuronally specific answers to this question. For example, enhancement of the sensory responsivity of LC neurons may contribute, perhaps through their extensive cortical projections, to the characteristic intensification of certain kinds of perceptual experience produced by hallucinogens. In the cerebral cortex, enhancement of the prolonged, late, asynchronous component of glutamatergic transmission by hallucinogens may underlie some of the cognitive and perceptual distortions produced by these drugs. Figure 3 depicts the enhancement of glutamatergic transmission by both 5 -HT inputs from the raphe nuclei and NE inputs from the $\mathrm{LC}$, acting via $5-\mathrm{HT}_{2 \mathrm{~A}}$ and $\alpha_{1}$ receptors, respectively. We hypothesize that hallucinogen-induced excesses in glutamatergic transmission are detrimental to cortical information processing; certain distinctive features of the effects of hallucinogens, such as distortions in perceptual and cognitive function, could fit into this framework. We suggest that an increase in asynchronous glutamatergic transmission could be responsible for the hallucinogeninduced hyperfrontal metabolic pattern that has been found recently in human brain- imaging studies (Vollenweider et al. 1997). A similar hyperfrontal pattern has also been found in acute, but not chronic, schizophrenic patients (Vollenweider et al. 1997). Ultimately, insight into how hallucinogens alter cortical information processing may provide clues about mechanisms underlying naturally occurring psychotic states.

\section{ACKNOWLEDGMENTS}

This article was prepared with support from the National Institute of Mental Health and the State of Connecticut.

\section{REFERENCES}

Aghajanian GK (1980): Mescaline and LSD facilitate the activation of locus coeruleus neurons by peripheral stimuli. Brain Res 186:492-498

Aghajanian GK (1995): Electrophysiology of serotonin receptor subtypes and signal transduction mechanisms. In Bloom FE, Kupfer DJ (eds), Psychopharmacology: The Fourth Generation of Progress. New York, Raven Press, pp 451-460

Aghajanian GK, Foote WE, Sheard MH (1968): Lysergic acid diethylamide: Sensitive neuronal units in the midbrain raphe. Science 161:706-708

Aghajanian GK, Foote WE, Sheard MH (1970): Action of psychotogenic drugs on single midbrain raphe neurons. J Pharmacol Exp Ther 171:178-187

Aghajanian GK, Haigler HJ (1975): Hallucinogenic indoleamines: Preferential action upon presynaptic serotonin receptors. Psychopharmacology 1:619-629

Aghajanian GK, Haigler HJ, Bloom FE (1972): Lysergic acid diethylamide and serotonin: Direct actions on serotonin-containing neurons in rat brain. Life Sci 11:615-622 
Aghajanian GK, Marek GJ (1997): Serotonin induces excitatory postsynaptic potentials in apical dendrites of neocortical pyramidal cells. Neuropharmacology 36:589-599

Aghajanian GK, Marek GJ (1998): Serotonin 5- $\mathrm{HT}_{2 \mathrm{~A}}$ receptors enhance asynchronous excitatory transmission in pyramidal cells (layer V) of prefrontal cortex. Soc Neurosci Abs 24:1366

Araneda R, Andrade R (1991): 5-Hydroxytryptamine 2 and 5-hydroxytryptamine ${ }_{1 \mathrm{~A}}$ receptors mediate opposing responses on membrane excitability in rat association cortex. Neuroscience 40:399-412

Aston-Jones G, Bloom FE (1981): Norepinephrine-containing locus coeruleus neurons in behaving rats exhibit pronounced responses to non-noxious environmental stimuli. J Neurosci 1:87-900

Balestrieri A, Fontanari D (1959): Acquired and crossed tolerance to mescaline, LSD-25, and BOL-148. Arch Gen Psychiat 1:279-282

Bonson KR, Buckholtz JW, Murphy DL (1996): Chronic administration of serotonergic antidepressants attenuates the subjective effects of LSD in humans. Neuropsychopharmacology 14:425-436

Cedarbaum JM, Aghajanian GK (1978): Activation of locus coeruleus neurons by peripheral stimuli: Modulation by a collateral inhibitory mechanism. Life Sci 23:1383-1392

Chiang C, Aston-Jones G (1993): A 5-hydroxytryptamine agonist augments $\gamma$-aminobutyric acid and excitatory amino acid inputs to noradrenergic locus coeruleus neurons. Neuroscience 54:409-420

Dählstrom A, Fuxe K (1964): Evidence for the existence of monoamine containing neurons in the central nervous system. I. Demonstration of monoamines in the cell bodies of brain stem neurons. Acta Physiol Scand 6:1-55

Freedman DX (1961): Effects of LSD-25 on brain serotonin. J Pharmacol Exp Ther 134:160-166

Gaddum JH, Hammeed KA (1954): Drugs that antagonize 5-hydroxytryptamine. Br J Pharmacol 9:240-248

Gellman RL, Aghajanian GK (1993): Pyramidal cells in piriform cortex receive a convergence of inputs from monoamine activated GABAergic interneurons. Brain Res 600:63-73

Glennon RA (1990): Do classical hallucinogens act as 5-HT2 agonists or antagonists? Neuropsychopharmacology 3:509-517

Glennon RA, Titeler M, McKenney JD (1984): Evidence for $5-\mathrm{HT}_{2}$ involvement in the mechanism of action of hallucinogenic agents. Life Sci 35:2502-2511

Goda Y, Stevens CF (1994): Two components of transmitter release at a central synapse. Pro. Natl Acad Sci USA 91:12942-12946

Haigler HJ, Aghajanian GK (1973): Mescaline and LSD: Direct and indirect effects on serotonin-containing neurons in brain. Eur J Pharmacol 21:53-60

Hoyer D, Clarke DE, Fozard R, Hartig PR, Martin GR, Mylecharane EJ, Saxena PR, Humphrey PPA (1994): VII. International Union of Pharmacology classification of receptors for 5-hydroxytryptamine (serotonin). Pharmacol Revs 46:157-203

Isbell H, Logan CR (1957): Studies on the diethylamide of lysergic acid (LSD-25). Arch Gen Psychiat 77:350-358
Jakab RL, Goldman-Rakic PS (1998): 5-Hydroxytryptamine 2 A serotonin receptors in the primate cerbral cortex: Possible site of action of hallucinogenic and antipsychotic drugs in pyramidal cell apical dendrites. Proc Natl Acad Sci 95:735-740

Kennett GA, Wood MD, Bright F, Trail B, Riley G, Holland V, Avenell KY, Stean T, Upton N, Bromidge S, Forbes IT, Brown AM, Middlemiss DN, Blackburn TP (1997): SB 242084, a selective and brain penetrant 5-HT2C receptor antagonist. Neuropharmacology 36:609-620

Li C, Bazbek CL, Davletov A, Sudhof TC (1995): Distinct $\mathrm{Ca} 2+$ and $\mathrm{Sr} 2+$ binding properties of synaptotagmins. J Biol Chem 270:24898-24902

Lopez-Gimenez JF, Mengod G, Palacios JM, Vilaro MT (1997): Selective visualization of rat brain 5- $\mathrm{HT}_{2 \mathrm{~A}}$ receptors by autoradiography with [3H]MDL 100,907. Naunyn-Schmiedeberg's Arch Pharmacol 356:446-454

Marek GJ, Aghajanian GK (1996a): LSD and the phenethylamine hallucinogen DOI are potent partial agonists at $5-\mathrm{HT}_{2 \mathrm{~A}}$ receptors on neurons in the rat piriform cortex. J Pharmacol Exp Ther 278:1373-1382

Marek GJ, Aghajanian GK (1996b): Serotonergic amplification of apically derived EPSPs in neocortical pyramidal cells. Soc Neurosci Abs 22:1323

Marek GJ, Aghajanian GK (1998a): 5-HT-induced EPSCs in neocortical layer $\mathrm{V}$ pyramidal cell of prefrontal cortex: Suppression by $\mu$ opiate receptor activation. Neuroscience 86:485-497

Marek GJ, Aghajanian GK (1998b): Serotonin 2 A receptorinduced EPSCs in layer V pyramidal cells of prefrontal cortex: Block by group II/III metabotropic glutamate agonists. Soc Neurosci Abs 24:1366

Mengod G, Pompeiano M, Martinez-Mir MI, Palacios JM (1990): Localization of the mRNA for the 5- $\mathrm{HT}_{2}$ receptor by in situ hybridization histochemistry. Correlation with the distribution of receptor sites. Brain Res 524:139-143

Pazos A, Palacios JM (1985): Quantitative autoradiographic mapping of serotonin receptors in the rat brain. I. Serotonin-1 receptors. Brain Re. 346:205-230

Rapport MM, Green AA, Page IH (1948): Serum vasoconstrictor (serotonin). IV. Isolation and characterization. J Biol Chem 176:1243-1251

Rasmussen K, Aghajanian GK (1986): Effects of hallucinogens on spontaneous and sensory-evoked locus coeruleus unit activity in the rat: Reversal by selective $5-\mathrm{HT}_{2}$ antagonists. Brain Res 385:95-400

Rasmussen K, Aghajanian GK (1988): Potency of antipsychotics in reversing the effects of a hallucinogenic drug on locus coeruleus neurons correlates with $5-\mathrm{HT}_{2}$ binding affinity. Neuropsychopharmacology 1:101-107

Resnick O, Krus DM, Raskin M (1964): LSD-25 action in normal subjects treated with a monoamine oxidase inhibitor. Life Sci 3:1207-1214

Resnick O, Krus DM, Raskin M (1965): Accentuation of the psychological effects of LSD-25 in normal subjects treated with reserpine. Life Sci 4:1433-1437

Sanders-Bush E, Burris KD, Knoth K (1988): Lysergic acid diethylamide and 2,5-dimethoxy-4-methylamphetamine are partial agonists at serotonin receptors linked to phosphoinositide hydrolysis. J Pharmacol Exper Therapeu 246:924-928 
Shaw E, Woolley DW (1956): Some serotonin-like activities of lysergic acid diethylamide. Science 124:121-123

Sheldon PW, Aghajanian GK (1990): Serotonin (5-HT) induces IPSPs in pyramidal layer cells of rat piriform cortex: Evidence for the involvement of a 5- $\mathrm{HT}_{2}$-activated interneuron. Brain Res 506:62-69

Tanaka E, North RA (1993): Actions of 5-hydroxytryptamine on neurons of the rat cingulate cortex. J Neurophys 69:1749-1757

Titeler M, Lyon RA, Glennon RA (1988): Radioligand binding evidence implicates the brain $5-\mathrm{HT}_{2}$ receptor as a site of action for LSD and phenylisopropylamine hallucinogens. Psychopharmacology 94:213-216

Twarog BM, Page IH (1953): Serotonin content of some mammalian tissues and urine and a method for its determination. Am J Physiol 175:157-161
Vollenweider FX, Leenders KL, Scharfetter C, Maguire P, Stadelmann O, Angst J (1997): Positron emission tomography and fluorodeoxyglucose studies of metabolic hyperfrontality and psychopathology in the psilocybin model of psychosis. Neuropsychopharmacology 16:357-372

Willins DL, Deutch AY, Roth BL (1997): Serotonin 5- $\mathrm{HT}_{2 \mathrm{~A}}$ receptors are expressed on pyramidal cells and interneurons in the rat cortex. Synapse 27:79-82

Wolbach AB, Miner EJ, Isbell H (1962): Comparison of psilocin with psilocybin, mescaline, and LSD-25. Psychopharmacologia 3:219-223

Woolley DW, Shaw W (1954): A biochemical and pharmacological suggestion about certain mental disorders. Proc Natl Acad Sci 40:228-231 